\title{
GIS-based Study on the Susceptibility of Dubai Creek (UAE) to Eutrophication
}

\author{
Tarig A. Ali*, Maruf Mortula, Serter Atabay \\ Department of Civil Engineering, American University of Sharjah, \\ Sharjah, United Arab Emirates
}

Received: 29 March 2016

Accepted: 11 June 2016

\begin{abstract}
Rapid urbanization in the UAE has led to some environmental implications, one of which concerns Dubai Creek - a major attraction in the city of Dubai. The creek's water quality monitoring program showed increased concentrations of phosphorus- and nitrogen-based nutrients starting in 2008 and 2009. The creek has since been through redundant eutrophication, which has been attributed to the high levels of nutrients in addition to the creek's poor flushing and irregular circulation processes. The aim of this study was to (a) assess the susceptibility of the creek to eutrophication considering its principal factors, and (b) to identify the pattern of this process (i.e., seasonal, cyclic, etc.). Principal component analysis was used to identify the principal factors from nitrates, phosphates, total nitrogen, chlorophyll-a, dissolved oxygen, and turbidity, which were collected as quarterly averages in 2012 and 2013. Logistic regression was utilized to assess the susceptibility of the creek to eutrophication considering the principal factors obtained by PCA. The analysis showed that three different factors, which included at least nitrates or phosphates, have contributed to eutrophication in every quarter of the year in the period of study. Further analysis showed weak correlation between principal factors of eutrophication in consecutive quarters. However, strong correlations were observed between these factors when the same quarters over the period of the study were considered, suggesting a possible seasonal pattern.
\end{abstract}

Keywords: Dubai Creek, nutrients, eutrophication, logistic regression

\section{Introduction}

The levels of nutrients in a water body play an essential role in identifying the level of pollution [1]. Algae and other forms of plants overgrow in the water column when nutrient levels increase critically, resulting in an imbalanced aquatic ecosystem (eutrophication) that favors some organisms over others. Eutrophication is normally assessed using different thresholds based

*e-mail: atarig@aus.edu on the concentrations of nutrients and chlorophyll-a in the water [2-3]. However, these criteria do not specify the integral impact of nutrients and chlorophyll-a - the conditioning factors for eutrophication [4]. Eutrophication has been mainly attributed to human activities, including urbanization, agricultural, and industrial activities. Eutrophication was the subject of numerous research studies over the past two decades, including assessment of its risks [5-8], environmental and economic impacts [912], its impact on benthic fauna [13], an assessment of nutrient enrichment impact in estuaries [14], and numerical modeling of eutrophication [15-16]. Dubai has rapidly 
developed in the past decade and the vast urbanization has resulted in a significant impact on the environment.

Dubai Creek is a 14-km saltwater body located at the heart of Dubai and is mainly used for trade, transport, and recreation. The major source of the creek's nutrient pollution is the treated sewage discharge from Al-Aweer Sewage Treatment Plant [17-18]. The Dubai Municipality (DM) monitors the creek's water quality at 10 stations and the measured water quality parameters include phosphates, nitrates, total nitrogen, chlorophyll-a, turbidity, dissolved oxygen, salinity, and $\mathrm{pH}$. Water quality data recorded in the past few years showed a pattern of increased concentrations of nutrients and chlorophyll-a in the creek to levels that exceeded the seasonal averages set in the Organization for Economic Cooperation and Development (OECD) criteria for assessing eutrophic status and the numeric nutrients standard of the U.S. Environmental Protection Agency's (EPA) national nutrient strategy [19-20]. This situation has created serious concern in the aftermath of the major algal bloom event of 2008 (aka redtide), which caused catastrophic fish kills in the creek and devastated the coasts of Dubai and UAE. Therefore, the vulnerability of the creek to eutrophication needs to be assessed. Based on the success of logistic regression (LR) in numerous studies - especially those that were carried out to map the susceptibility of floods [21], landslides [22], and also based on the success in wetland assessment and management using geospatial techniques [23] - this study is unique in the application of LR within the GIS environment to assess the susceptibility of the creek to eutrophication.

The objectives of the study were to identify the principal factors of eutrophication in the creek in every quarter during the period of study, to estimate the probability of occurrence of eutrophication in the creek to produce maps of the susceptibility of the creek to eutrophication, and to identify the processes that are responsible for eutrophication in the creek. LR is a multivariate statistical method that considers all of the independent variables (referred to as conditioning factors in this study) that influence the occurrence of the dependent variable [24]. The principal conditioning factors of eutrophication in the creek were estimated using the Principal Component Analysis (PCA) given the creek's water quality parameters, which were considered the initial factors before LR was utilized. This was an essential task because LR requires the use of factors that are uncorrelated or in other words have maximum variances.

\section{Study Area and Data}

Dubai Creek is located in Dubai, United Arab Emirates (UAE) and is spatially identified by a minimum enclosing rectangle that has left top coordinates of $25^{\circ} 16^{\prime} 30.8^{\prime \prime} \mathrm{N}, 55^{\circ} 17^{\prime} 30^{\prime \prime} \mathrm{E}$ and right bottom coordinates of $25^{\circ} 10^{\prime} 58.5^{\prime \prime} \mathrm{N}, 55^{\circ} 21^{\prime} 6.9^{\prime \prime} \mathrm{E}$. The creek is composed of a narrow channel segment surrounded by urban and vegetation areas on the two banks, while the lagoon part is surrounded by bare lands, a sanctuary, and undeveloped areas. The creek extends for about $14 \mathrm{~km}$ and has a surface area of $8 \mathrm{~km}^{2}$, of which about $4.6 \mathrm{~km}^{2}$ is the lagoon's area. Major sources of nutrients into the creek include the discharge of the treated sewage from the Al Aweer Sewage Processing Plant and surface runoff from urban and vegetation areas (Fig. 1).

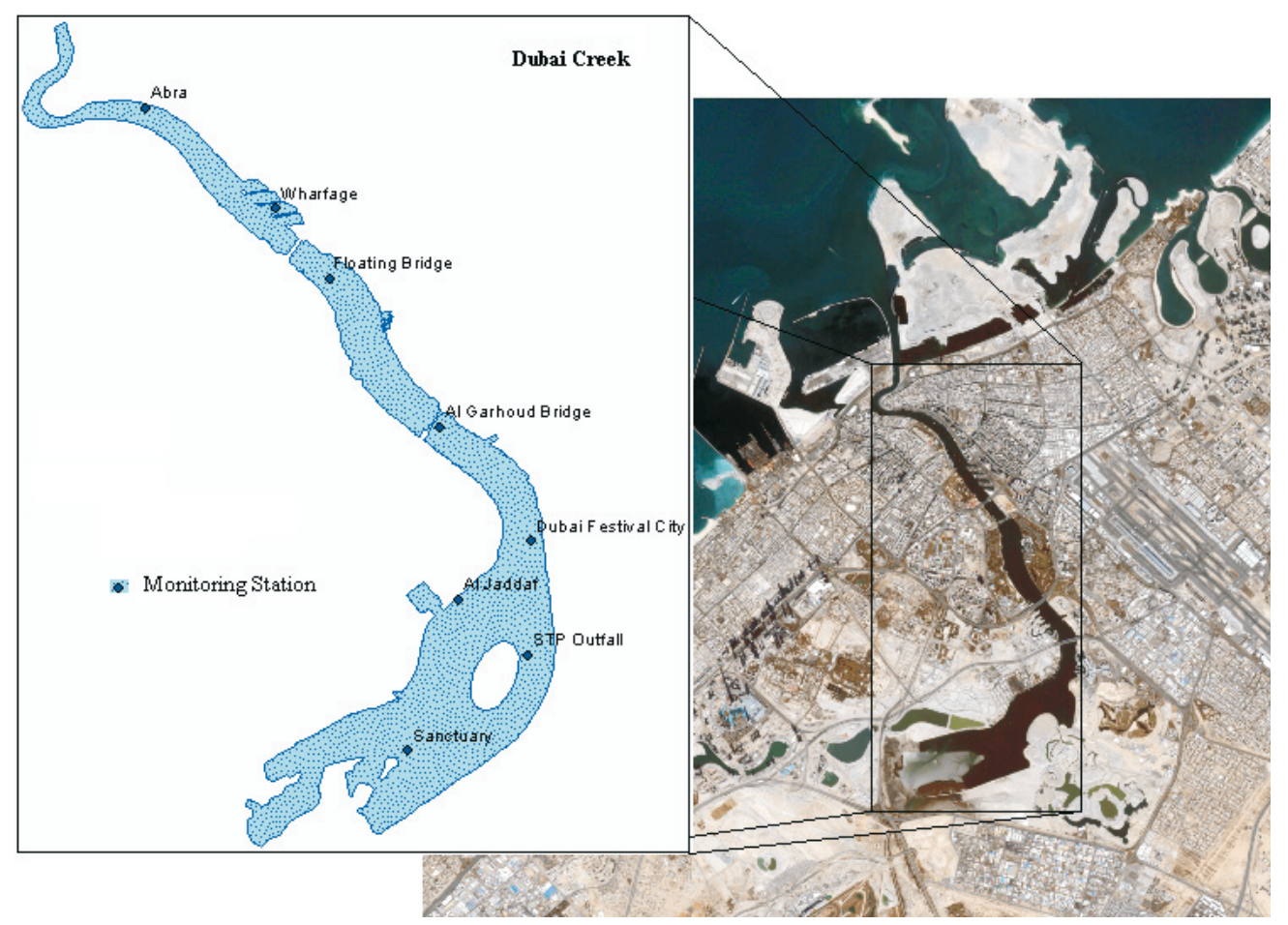

Fig. 1. The geographic location of Dubai Creek and the water quality monitoring stations in Dubai, UAE. 
Table 1. Values of water quality parameters in the first quarter of 2012.

\begin{tabular}{|c|c|c|c|c|c|c|c|c|}
\hline Stations & $\begin{array}{c}\text { Salinity } \\
\mathrm{ppt}\end{array}$ & $\mathrm{pH}$ & $\begin{array}{c}\text { Chlorophyll-a } \\
\mathrm{mg} / \mathrm{L}\end{array}$ & $\begin{array}{c}\text { DO Conc } \\
\mathrm{mg} / \mathrm{L}\end{array}$ & $\begin{array}{c}\text { Turbidity } \\
\text { N.T.U }\end{array}$ & $\begin{array}{c}\text { Nitrates } \\
\mathrm{mg} / \mathrm{L}\end{array}$ & $\begin{array}{c}\text { Total Nitrogen } \\
\mathrm{mg} / \mathrm{L}\end{array}$ & $\begin{array}{c}\text { Phosphates } \\
\mathrm{mg} / \mathrm{L}\end{array}$ \\
\hline Creek Mouth & 38.68 & 8.05 & 5.3 & 6.91 & 1.5 & 0.74 & 2.47 & 0.11 \\
\hline Hayat Regency & 39.81 & 8.08 & 6.8 & 7.31 & 1.5 & 0.47 & 1.74 & 0.05 \\
\hline Abra & 38.23 & 8.04 & 8.2 & 6.2 & 1.5 & 1.02 & 2.92 & 0.14 \\
\hline Wharfage & 37.76 & 8.14 & 40.8 & 7.36 & 1.5 & 1.14 & 3.47 & 0.16 \\
\hline Floating Bridge & 36.05 & 8.29 & 51.2 & 11.21 & 1 & 1.7 & 5.44 & 0.16 \\
\hline Al Garhoud Bridge & 36.8 & 7.96 & 17.9 & 7.23 & 1.5 & 1.94 & 6.04 & 0.19 \\
\hline Dubai Festival City & 34.52 & 8.05 & 13.3 & 7.9 & 1 & 3.22 & 8.2 & 0.31 \\
\hline $\begin{array}{c}\text { Sewage Treatment } \\
\text { Plant (STP) Outfall }\end{array}$ & 36.08 & 8.08 & 11.5 & 7.61 & 1 & 8.75 & 24.7 & 0.95 \\
\hline Jaddaf & 33.67 & 8.21 & 3.5 & 7.97 & 1 & 3.46 & 11.55 & 0.28 \\
\hline Sanctuary & 36.54 & 8.27 & 6.4 & 8.88 & 1 & 1.72 & 5.95 & 0.23 \\
\hline
\end{tabular}

The water quality dataset used in this study was collected at the 10 monitoring stations over a two-year period from 2012 to 2013 and was provided by the Dubai Municipality as monthly averages in the following quarters: January-March (first quarter), April-June (second quarter), July-September (third quarter), and OctoberDecember (fourth quarter). The measured water quality parameters include phosphates, nitrates, total nitrogen, chlorophyll-a, turbidity, dissolved oxygen, salinity, and $\mathrm{pH}$. Table 1 shows the water quality dataset of the creek in the first quarter of 2012 for each monitoring station, which is presented herein as a sample of the dataset used in the period of study.

\section{Methods}

Logistic regression (LR) is a multivariate statistical analysis approach that considers all the conditioning factors (independent variables) that may influence the probability of occurrence of the dependent variable, in this case eutrophication [24]. The LR model can help in estimating the probability of occurrence of any event if its independent conditioning factors are known. LR has a function $\mathrm{f}(\mathrm{z})$ of the general simple form of Equation 1 [25]:

$$
f(z)=\frac{1}{1+e^{-z}}
$$

...where $\mathrm{f}(\mathrm{z})$ is the LR function and $\mathrm{z}$ is the dependent variable such that $1 \geq f(z) \geq 0$. The fact that the logistic function, $f(z)$, ranges from 0 to 1 is the main reason for LR model uniqueness and popularity as it describes the probability of occurrence of the dependent variable $\mathrm{z}$ as it varies with independent variables.

In the simplest form of the LR model, inclusion of many independent variables makes the model more robust. The main reasons for the selection of the LR method in this study were: (a) the range of the estimates of the LR function $\mathrm{f}(\mathrm{z})$ within 0 and 1 , which is useful in defining different levels of susceptibility of the creek to eutrophication; (b) the s-shaped graph of the LR function can help in describing the threshold criteria, which is commonly used in defining the eutrophic status of a water body, and (c) the LR model dependent variable, z, can model the combined effects of several conditioning factors, which describes the problem we are trying to address in this study. That is, the independent variable $\mathrm{z}$ is a linear combination of " $\mathrm{k}$ " independent uncorrelated multivariable observations $x_{1}, x_{2}, x_{3} \ldots, x_{k}$. The general equation of the simple LR, which was used in this study, is of the following form:

$$
\mathrm{z}=\mathrm{a}_{0}+\mathrm{a}_{1} \mathrm{x}_{1}+\mathrm{a}_{2} \mathrm{x}_{2}+\mathrm{a}_{3} \mathrm{x}_{3}+\cdots,+\mathrm{a}_{\mathrm{k}} \mathrm{x}_{\mathrm{k}}
$$

...where $a_{o}$ is the intercept and $a_{1}, a_{2}, a_{3}, \ldots, a_{k}$ are LR model coefficients.

The LR model was employed considering the principal conditioning factors of eutrophication in order to estimate the probability of its occurrence in the creek and further define levels of susceptibility to eutrophication. It is important to note that although the LR model is simple, it requires the selection of the "principal" independent variables (i.e., conditioning factors) that are uncorrelated (i.e., have the largest variance).

The general criteria for selecting the independent variables in the LR model require it to have the following characteristics: (a) they have relations with the dependent variable, (b) they have complete representation in the study area, (c) they vary spatially in the study area, (d) they are measurable, and (e) they are not repeated [2627]. Based on this criterion, the following six water quality parameters collected at the monitoring stations were selected as the initial conditioning factors given their relationships with eutrophication: chlorophyll-a, nitrates, total nitrogen, phosphates, turbidity, and dissolved oxygen. These parameters were originally collected as 
daily averages by Dubai Munciplaity, but were provided as monthly averages and were converted in this study to quarter-based averages in the following quarters: JanuaryMarch (first quarter), April-June (second quarter), JulySeptember (third quarter), and October-December (fourth quarter).

For high performance of the LR model, it is essential to ensure that the selected conditioning factors are independent and uncorrelated. In order to achieve this requirement and also to satisfy the main characteristics of the conditioning factors presented above, we used principal component analysis (PCA). This can help to avoid multicollinearity, which may lead to non-identifiable model coefficients (Härdle and Simar, 2012). In order to calculate the principal components, consider the " $\mathrm{k}$ " independent observations presented in equation (2) above and define covariance between $\mathrm{xi}$ and $\mathrm{xj}$ as shown below for $\mathrm{i}, \mathrm{j}=1,2,3, \ldots, \mathrm{k}[28-29]$ :

$$
\operatorname{Cov}\left(x_{i}, x_{j}\right)=\sigma^{2} R_{i, j}
$$

Let $\mu_{1}>\mu_{2}>\mu_{3}>\ldots>\mu_{k}>0$ be the eigenvalues of $R$ and let $\mathrm{q}_{1}, \mathrm{q}_{2}, \mathrm{q}_{3}, \ldots, \mathrm{q}_{\mathrm{k}}$ be the corresponding eigenvectors, which are normalized as shown below:

$$
q_{j}^{T} q_{j}=1
$$

The first principal component $\left(\mathrm{PC}_{1}\right)$ is a linear combination of the multivariable observations; $x$ 's shown in equation (2) that have the largest variance:

$$
P C_{1}=\sum_{i=1}^{k} q_{1 i} x_{i}
$$

The second principal component $\left(\mathrm{PC}_{2}\right)$ has the largest variance among all linear combinations of the multivariable observations, $x$ 's that are orthogonal to $\mathrm{PC}_{1}$.

$$
\mathrm{PC}_{2}=\sum_{\mathrm{i}=1}^{\mathrm{k}} \mathrm{q}_{2 \mathrm{i}} \mathrm{x}_{\mathrm{i}}
$$

The remaining principal components (third, fourth, fifth, and six, in this case) are computed using the same procedure shown above for obtaining $\mathrm{PC}_{1}$ and $\mathrm{PC}_{2}$.

\section{Results and Discussion}

The resulting principal components were classified in ArcGIS 10.1 using the quantile classification method, and frequency ratio (FR) analysis was carried out on the selected principal components (PCs) to obtain the frequency ratios, which were used to compute weights for every class. The LR model was then run in SPSS V.19 software to establish the relationship between eutrophication occurrence (dependent variable) and its conditioning factors (the selected PCs).
Principal component analysis (PCA) was carried out in ArcGIS 10.1 for the initial six conditioning factors in every quarter in the period of study. Sample PCA results, which include the correlation matrix of the initial conditioning factors as well as the principal components, are shown in Tables 2 and 3, respectively, for the first quarter of 2012. In this quarter, the correlations between nitrates, phosphates, and total nitrogen are high (above 0.96). The three principal components with the highest variance values in the first quarter of 2012 were $\mathrm{PC}_{4}, \mathrm{PC}_{5}$, and $\mathrm{PC}_{6}$. These are basically the conditioning factors that were later adopted in the LR model as independent variables.

In the data of the first quarter of 2012, the most significant component was $\mathrm{PC}_{4}$, which illustrated a high positive contribution from nitrates and a negative contribution from total nitrogen. One reason for the negative contribution from total nitrogen could be its recorded high concentration at the STP Outfall station the second station from the bottom of the creek. The second significant principal component was $\mathrm{PC}_{5}$, which illustrated high positive contribution from turbidity and a negative contribution from phosphates. The record high concentration of phosphates at the STP Outfall station could be the reason for the negative contribution from phosphates. Nitrates and dissolved oxygen have approximately the same level of contribution to this principal component. The third significant principal component was $\mathrm{PC}_{2}$, which illustrated high positive contribution from total nitrogen and a positive contribution from nitrates. The fourth significant principal component was $\mathrm{PC}_{6}$, which illustrated high positive contribution from phosphates. The principal components $\mathrm{PC}_{4}, \mathrm{PC}_{5}$, and $\mathrm{PC}_{6}-$ which have respective high contributions from nitrates, turbidity, and phosphates - were selected as the principal conditioning factors of eutrophication in this quarter.

The LR model was then run in SPSS V.19 software to establish the relationship between eutrophication occurrence and its conditioning factors in this quarter, and accordingly the LR model equation (2) can be re-written with the coefficients as:

$$
\begin{gathered}
\mathrm{Z}=-0.545+0.212\left(\mathrm{PC}_{4}\right)+0.084 \\
\left(\mathrm{PC}_{5}\right)+0.187\left(\mathrm{PC}_{6}\right)
\end{gathered}
$$

The probability of occurrence of eutrophication in the creek in this quarter was estimated by running equations (7) and then equation (1) in ArcGIS 10.1 and is shown in Fig. 2. The map of the susceptibility of the creek to eutrophication was then created from the probability of occurrence map using the quantile classification method and is shown in Fig. 3.

The maps of probability of occurrence of eutrophication and susceptibility of the creek to eutrophication in the second, third, and fourth quarters of 2012 are shown in Figs 4 and 5, respectively.

In the second quarter of 2012, high correlations were observed between the following factors: chlorophyll-a and nitrates, chlorophyll-a and phosphates, nitrates and 
Table 2. The correlation matrix for the six initial conditioning factors in the first quarter of 2012.

\begin{tabular}{|c|c|c|c|c|c|c|}
\hline Layers & Chl-a & Nitrates & Phosphates & Total nitrogen & Dissolved Oxygen & Turbidity \\
\hline Chl-a & & -0.30726 & -0.4028 & -0.33871 & 0.38275 & 0.42996 \\
\hline Nitrates & & & 0.96715 & 0.99392 & -0.17773 & -0.43111 \\
\hline Phosphates & & & & 0.96463 & -0.16515 & -0.50181 \\
\hline Total nitrogen & & & & & -0.12409 & -0.48854 \\
\hline Dissolved Oxygen & & & & & & \\
\hline Turbidity & & & & & & \\
\hline
\end{tabular}

Table 3. Principal components (PC) for the six initial conditioning factors in the first quarter of 2012.

\begin{tabular}{|c|c|c|c|c|c|c|}
\hline Layers & PC1 & PC2 & PC3 & PC4 & PC5 & PC6 \\
\hline Chl-a & 0.79666 & 0.16361 & -0.03003 & -0.00621 & -0.01023 & -0.00011 \\
\hline Nitrates & -0.05097 & 0.33285 & -0.11649 & 0.98461 & 0.2045 & -0.11362 \\
\hline Phosphates & -0.00601 & 0.02902 & -0.00196 & 0.15843 & -0.2156 & 0.99309 \\
\hline Total nitrogen & -0.15543 & 0.92813 & 0.04003 & -0.33127 & -0.05363 & 0.01363 \\
\hline Dissolved Oxygen & 0.03133 & 0.005 & 0.98186 & 0.0929 & 0.16062 & 0.02272 \\
\hline Turbidity & 0.00622 & -0.01188 & -0.14097 & -0.19539 & 0.99964 & 0.2426 \\
\hline
\end{tabular}

phosphates, dissolved oxygen and total nitrogen, and dissolved oxygen and turbidity. The high correlations between dissolved oxygen on the one hand and total nitrogen and turbidity on the other were notable. The principal components in this quarter were $\mathrm{PC}_{2}, \mathrm{PC}_{3}$, and $\mathrm{PC}_{5}$, with major contributions from phosphates,

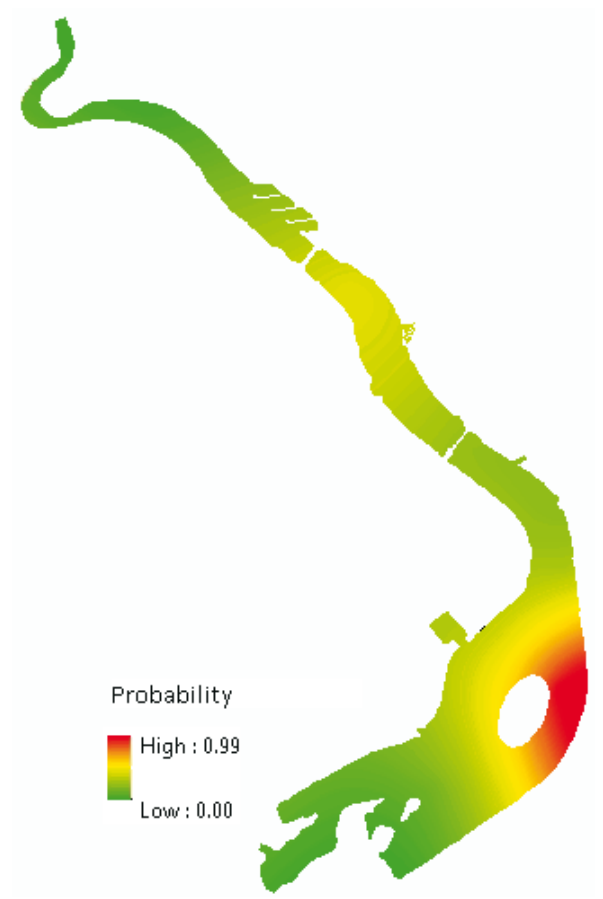

Fig. 2. The probability of occurrence of eutrophication in the creek in the first quarter of 2012. chlorophyll-a, and total nitrogen, respectively. In the third quarter of 2012, no high correlations were observed between the initial factors. The principal components in this quarter were $\mathrm{PC}_{3}, \mathrm{PC}_{4}$, and $\mathrm{PC}_{5}$, with major contributions from chlorophyll-a, phosphates, and nitrates, respectively. In the fourth quarter of 2012 ,

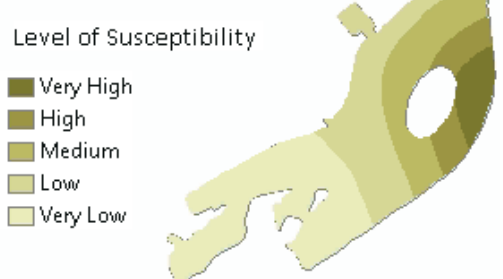

Fig. 3. The levels of susceptibility to eutrophication obtained with PCA and LR in the first quarter of 2012. 


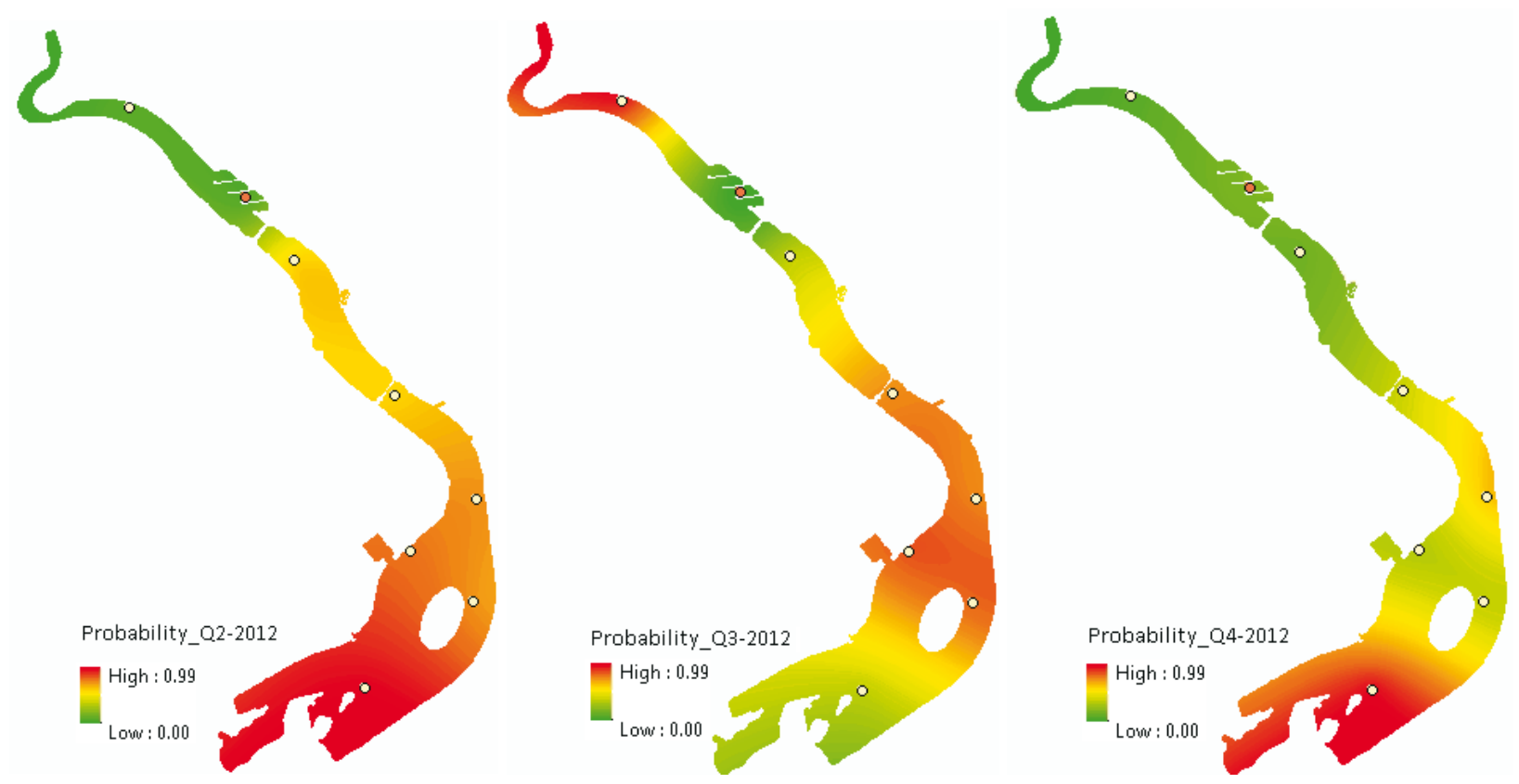

Fig. 4. Maps of probability of occurrence of eutrophication in the second, third, and fourth quarters of 2012.

high correlations were observed between phosphates, total nitrogen, and nitrates. Also observed was a rather medium to high correlation between dissolved oxygen and turbidity. The principal components in this quarter were $\mathrm{PC}_{2}, \mathrm{PC}_{4}$, and $\mathrm{PC}_{5}$, with major contributions from total nitrogen, turbidity, and nitrates, respectively. Following the LR approach used with the first quarter of 2012 data, the maps of the probability of occurrence of eutrophication in the three quarters of 2012 were created. Accordingly, maps of the susceptibility of the creek to eutrophication were produced. The results suggest that susceptibility to eutrophication in every quarter in this period was directly influenced by three conditioning factors that included at least nitrates or phosphates.

In the first quarter of 2013, high correlations were observed between chlorophyll-a and dissolved oxygen, chlorophyll-a and turbidity, and nitrates and total nitrogen. In the second quarter of 2013, high correlations were observed between phosphates and nitrates and then phosphates and total nitrogen. In the third quarter of 2013, high correlations were observed between dissolved oxygen and turbidity, phosphates and nitrates,

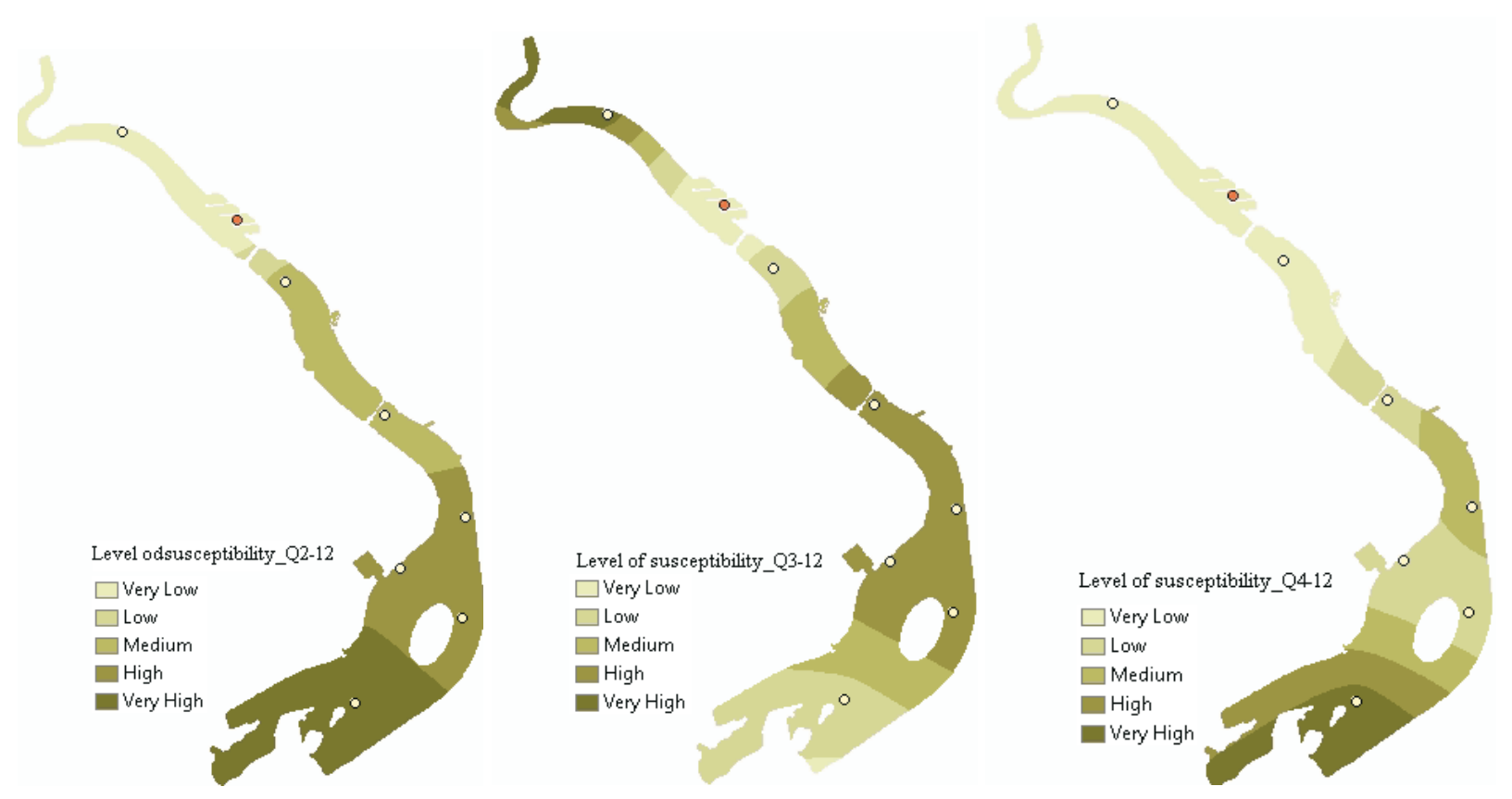

Fig. 5. Maps of susceptibility of the creek to eutrophication in the second, third, and fourth quarters of 2012. 
and phosphates and total nitrogen. In the fourth quarter of 2013, high correlations were observed between chlorophyll-a and dissolved oxygen, chlorophyll-a and turbidity, and dissolved oxygen and turbidity. Following the same LR approach used with 2012 data, the maps of the probability of occurrence of eutrophication in the creek in the four quarters of 2013 were created, followed by maps of the susceptibility of the creek to eutrophication. Based on the identified PCs in all four quarters of 2013 and their respective major contributing factors, at least one of nitrates or phosphates was identified as a major contributing factor to the respective principal components in all quarters of 2013.

Comparing the PCA results for 2012 and 2013, it was evident that two of the major contributing factors to the principal components in every quarter of 2012 were the same in the respective quarter in 2013. For example, nitrates and phosphates were two of the major contributing factors to the PCs in quarter 1 in both 2012 and 2013. This can indicate a seasonal pattern that characterizes eutrophication and its major factors in the creek in the period of study.

Further investigation was carried out using linear regression analysis to study the relationships between the probability of occurrence of eutrophication in any quarter (as estimated with LR) in the period of study and the previous quarter's concentrations of nitrates, phosphates, and chlorophyll-a, considered individually and jointly [30-31]. The selection of these factors in this analysis was based on the following facts: (a) at least one of the nitrates or phosphates was one of the major contributors to the principal components in all eight quarters of 2012 and 2013, and (b) chlorophyll-a is the common parameter used by many threshold-based guidelines for assessing eutrophication in water bodies. Table 4 below lists the resulted R-square values obtained through regression analysis for the relationships between the probability of occurrence of eutrophication in a quarter and the selected factor combinations in the previous quarter. Low values of $\mathrm{R}$-square were obtained for the relationship between the occurrence of eutrophication in a quarter and the levels of each of the three factors in the preceding quarter when considered individually. This is an indication that the use of a single parameter to assess the creek's eutrophication status can be misleading. However, high correlation coefficients were obtained for this relationship when the combination of all three factors was considered (column 8 in Table 4). This outcome indicated the fact that the assessment of the eutrophication status in the creek would be much more robust when a combination of more than one parameter is used.

\section{Conclusion}

PCA was used to identify the main conditioning factors of eutrophication in Dubai Creek. LR modeling was used to study the susceptibility of the creek to eutrophication based on the principal conditioning factors identified by PCA. Accordingly, maps of probability of occurrence of eutrophication in the creek as well as the levels of susceptibility of the creek to eutrophication were created. Analysis showed that susceptibility of the creek to eutrophication in any quarter of the year during the period of study was influenced by three conditioning factors, which included nitrates or phosphates. Therefore, the use of threshold criteria based on the value of one or two parameters to assess the "eutrophic" status in the creek can be misleading. The analysis showed weak correlations between principal factors of eutrophication in consecutive quarters of the year during the period of study. Further analysis showed stronger correlations between these factors when same quarters over the twoyear period of study were considered, which suggests a possible seasonal pattern. Furthermore, weak correlations were obtained between the occurrence of eutrophication in any quarter and the levels of nitrates, phosphates, and chlorophyll-a in the creek's water in the following quarter (when considered individually). Stronger correlations were obtained between the occurrence of eutrophication in any quarter and the levels of these factors in the following quarter (when considered jointly).

Table 4. R-square values of regression analysis of the relationships between the occurrence of eutrophication in a quarter and the values of the selected factor combinations in the preceding quarter.

\begin{tabular}{|c|c|c|c|c|c|c|c|}
\hline \multirow{2}{*}{$\begin{array}{l}\text { Quarters in } \\
\text { consideration }\end{array}$} & \multicolumn{7}{|c|}{$\begin{array}{l}\text { R-square values (\%) of relationships of the occurrence of eutrophication between the consecutive } \\
\text { quarters shown in column } 1\end{array}$} \\
\hline & $\mathrm{NT}^{1}$ & $\mathrm{PHOS}^{2}$ & $\mathrm{CLA}^{3}$ & $\mathrm{NT}^{1}+\mathrm{PHOS}^{2}$ & $\mathrm{NT}^{1}+\mathrm{CLA}^{3}$ & $\mathrm{PHOS}^{2}+\mathrm{CLA}^{3}$ & $\mathrm{NT}^{1}+\mathrm{PHOS}^{2}+\mathrm{CLA}^{3}$ \\
\hline Q1 \& Q2-2012 & 45 & 52 & 48 & 59 & 56 & 59 & 73 \\
\hline Q2 \& Q3-2012 & 33 & 58 & 29 & 61 & 42 & 63 & 70 \\
\hline Q3 \& Q4-2012 & 28 & 63 & 64 & 63 & 66 & 69 & 76 \\
\hline Q4-124 \& Q1-135 & 29 & 48 & 53 & 52 & 58 & 58 & 79 \\
\hline Q1 \& Q2-2013 & 34 & 51 & 50 & 52 & 55 & 55 & 75 \\
\hline Q2 \& Q3-2013 & 59 & 60 & 44 & 65 & 62 & 64 & 74 \\
\hline Q3 \& Q4-2013 & 45 & 58 & 56 & 60 & 59 & 61 & 78 \\
\hline
\end{tabular}

${ }^{1}$ Nitrate, ${ }^{2}$ Phosphate, ${ }^{3}$ Chlorophyll-a, ${ }^{4}$ 2012, ${ }^{5} 2013$ 


\section{Acknowledgements}

The authors acknowledge Dubai Municipality for supporting this study by providing the water quality monitoring data. The authors also acknowledge support from the American University of Sharjah Office of Researh and Grdaute Studies through Faculty Research Grants (FRG14-2-16) and (FRG12-2-24).

\section{References}

1. LAND L. Chesapeake Bay nutrient pollution: Contribution from the land application of sewage sludge in Virginia. Mar Pollut. Bull., 64 (11), 2305, 2012.

2. REYNOLDS C. Ecology of Phytoplankton. Cambridge University Press, NewYork, 2006.

3. ANSARI A., GILL S., LANZA G., RAST W. Eutrophication: Causes, Consequences and Control. Springer, New York, 2010.

4. TROOST T., DE KLUIJVER A., LOS F. Evaluation of eutrophication variables and thresholds in the Dutch North Sea in a historical context-A model analysis. J of Marine Syst, 134, 45, 2014.

5. BRICKER S., CLEMENT C., PIRHALLA D., ORLANDO S., FARROW D. National Estuarine Eutrophication Assessment: Effects of Nutrient Enrichment in the Nation's Estuaries. NOAA, National Ocean Service, Special Projects Office and the National Centers for Coastal Ocean Science, Silver Spring, MD, 71, 1999.

6. HAVENS K., FUKUSHIMA T., XIE P., IWAKUMA T., JAMES R., TAKAMURAN., HANAZATOT., YAMAMOTO T. Nutrient dynamics and the eutrophication of shallow lakes Kasumigaura (Japan), Donghu (PR China), and Okeechobee (USA). Environmental Pollution, 111 ( 2), 263, 2001.

7. TETT P., GOWEN R., MILLS D., FERNANDES T., GILPIN L., HUXHAM M., KENNINGTON K., READ P., SERVICE M., WILKINSON M., MALCOLM S. Defining and detecting undesirable disturbance in the context of marine eutrophication. Mar Pollut Bull, 55, 282, 2006.

8. KITSIOU D., KARYDIS M. Coastal marine eutrophication assessment: a review on data analysis. Environ. Int. 37, 778, 2011.

9. BORJA A., DAUER D. Assessing the environmental quality status in estuarine and coastal systems: Comparing methodologies and indices. Ecol. Indic. 8, 331, 2008.

10. DIAZ R., ROSENBERG R. Introduction to environmental and economic consequences of hypoxia. Int. J. Water Res., 27, 71, 2011.

11. MOSS B., KOSTEN S., MEERHOFF M., BATTARBEE R., JEPPESEN E., MAZZEO N., HAVENS K., LACEROT G., LIU Z., DE MEESTER L., PAERL H., SCHEFFER M. Allied attack: climate change and eutrophication. Inland Waters, 1 (2), 101, 2011

12. GU Y., WANG Z., LU S., JIANG S., MU D., SHU Y. Multivariate statistical and GIS-based approach to identify source of anthropogenic impacts on metallic elements in sediments from the mid Guangdong coasts, China. Env. Pollut. 163, 248, 2012.

13. KARLSON K., ROSENBERG R., BONSDORFF E. Temporal and spatial large-scale effects of eutrophication and oxygen deficiency on benthic fauna in Scandina-vian waters - a review. Oceanogr. Mar. Biol. Ann. Rev. 40, 427, 2002.
14. PAINTING S., DEVLIN M., MALCOLM S., PARKER E., MILLS D., MILLS C., TETT P., WITHER A., BURT J., JONES R., WINPENNY K. Assessing the impact of nutrient enrichment in estuaries: Susceptibility to eutrophication. Mar Pollut Bull, 55, 74, 2007

15. TETT P. Marine eutrophication and the use of models. In: Huxham, M., Summer, D. (Eds.), Marine Eutrophication and the Use of Models, Science and Environmental Decision Making. Addison Wesley Longman/Pearson Education, London, 215, 2000.

16. FERNÁNDEZ P., GÓMEZ A., ALBA J., DÍAZ C., CORTEZÓN J. A model for describing the eutrophication in a heavily regulated coastal lagoon: Application to the Albufera of Valencia (Spain). J. of Env. Manag., 112, 340, 2012.

17. SAUNDERS J., AL ZAHED K., PATERSON D. The impact of organic pollution on the macro-benthic fauna of Dubai creek (UAE), Mar Pollut Bull, 54 (11), 1715, 2007.

18. ALI T., MORTULA M., ATABAY S. Study of Water Quality in Dubai Creek using DubaiSat-1 Multispectral Imagery. International Conference on Geo-Informatics in Resource Management and Sustainable Ecosystem (GRMSE2013), Wuhan, China. Communications in Computer and Information Science (CCIS), 398, 200, 2013

19. OECD. Eutrophication of Waters, Monitoring, Assessment and Control. Organisation for Economic Cooperation and Development, Paris, 1982.

20. EPA. National Nutrient Strategy, Nutrient Policy Data. Available from http://www2.epa.gov/nutrient-policy-data/ national-nutrient-strategy, accessed on June, 2014.

21. TEHRANY M., PRADHAN B., JEBUR M. Spatial prediction of flood susceptible areas using rule based decision tree (DT) and a novel ensemble bivariate and multivariate statistical models in GIS. J Hydrol, 504, 69, 2013.

22. OHLMACHER C., DAVIS C. Using multiple regression and GIS technology to predict landslide hazard in northeast Kansas, USA. Eng Geol, 69, 331, 2003.

23. GARG J.Wetland assessment, monitoring and management in India using geospatial techniques. J. of Env. Manag., 148, $112,2015$.

24. SHIRZADI A., SARO L., JOO O., CHAPI K. A GIS-based logistic regression model in rock-fall susceptibility mapping along a mountainous road: Salavat Abad case study, Kurdistan, Iran. Nat. Hazards, 64, 1639, 2012.

25. HOSMER D., LEMESHOW S., STURDIVANT R. Applied logistic regression. $3^{\text {rd }}$ Edition, Wiley Series in Probability and Statistics, Wiley, NY, 2013.

26. AYALEW L., YAMAGISHI H. The application of GIS-based logistic regression for landslide susceptibility mapping in the Kakuda-Yahiko Mountains, Central Japan. Geomorphology, 65, 15, 2005.

27. HÄRDLE W., SIMAR L. Applied multivariate statistical analysis. Berlin, Heidelberg: Springer Berlin Heidelberg, 2012.

28. JOLLIFFE I. Principal component analysis. 2nd Edition, New York: Springer, 2002

29. CANDÈS E., LI X., MA Y., WRIGHT J. Robust principal component analysis? J. ACM, 58 (3), article no. 11, 2011.

30. LONG J. Regression Models for Categorical and Limited Dependent Variables. Thousand Oaks, CA: Sage Publications, 1997.

31. LONG J., FREESE J. Regression Models for Categorical Dependent Variables Using Stata (Second Edition). College Station, TX: Stata Press, 2006. 